\title{
Learning, Thinking and Living Tokyo. Doing urban research in cultures radically different to that of our own
}

\author{
Darko Radović \\ Keio University, Tokyo, Japan \\ IKI \& co+labo Radović | Smart Communities \\ radovic@sd.keio.ac.jp
}

\begin{abstract}
In 20I I, at Keio University, Tokyo, we launched Measuring the non-Measurable, with academic and practitioners involved in production of space in ten cities of Asia (Tokyo, Bangkok, Beijing, Hong Kong, Singapore), Australia (Melbourne) and Europe (Barcelona, Belgrade, Copenhagen, Florence).

The intention of Mn'M was never to question the importance of quantifiable dimensions of life. One of its critical aims was to argue for an equally respectful treatment of other dimensions of knowing, as neither the quantifiable not the non-quantifiable alone can fully cover the key dimensions of the synthetic quality which we seek to live. The cities are always in and of a particular place, in and of a particular time. That double contextualisation makes their realities enormously dynamic and complex. The complexity itself and the groundedness in concrete, unique situations are the key aspects of being urban.
\end{abstract}

Keywords: Public Space; Tokyo; non-measurable; subjectivity; urbanity.

To cite this article:

Radovic, D. (2016). Learning, Thinking and Living Tokyo. Doing urban research in cultures radically different to that of our own. The Journal of Public Space, I (I), 35-42, DOI:

10.5204/jps.vlil.8

This article has been peer-reviewed and accepted for publication in The Journal of Public Space. Please see the Editorial Policies under the 'About' section of the journal website for further information.

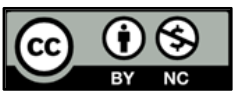

This work is licensed under a Creative Commons Attribution - Non Commercial 4.0 International License.

https://creativecommons.org/licenses/by-nc/4.0/ 
Learning, Thinking and Living Tokyo.

Doing urban research in cultures radically different to that of our own

I.

Several years ago, I took part in a very interesting event, a conference organised by one of the best European universities. Perfectly managed, the conference allowed plenty of time for spontaneous interaction and authentic discussions. One of the main threads focused at interim results of the research project, which was meticulously crafted by a local team, was an attempt to compare development patterns in a number of cities across the globe. The core team distributed research method guidelines and a pre-established presentation format, which facilitated easy and interesting comparisons. Having on mind the complexity of the themes addressed and opened within, and by that project, the discussions at the conference were wide-ranging, often provocative, and even truly polemological.

A then young researcher presented the sub-project which he headed in his home town, one of the provocative cases from Africa. When asked about the relevancy of the method, and how sensitive to local conditions (which were, of course, dramatically different from those in European, American, Asian and Australian examples) the predefined and finely crafted research methods were, his answer was unqualified; "Not at all!" he replied.

The local university was approached and funded by the reputable foreign institution. Research methods and communication tools were pre-established, based on the best of current urban theory and rigorously applied. As the focus was on comparisons, the comparisons were made, but the issues addressed and the themes raised locally had less then little relevance. For those who really knew the place and the problems facing it, the research questions were not relevant at all.

We all know that, as the Invisible Committee has succinctly summarised, "the past has given us far too many bad answers (...) not to see that the mistakes were in the questions themselves" (2009). The questions of this perfectly intended, decidedly rebellious and truly critical research project, as those of many similar projects before, were still crafted within the ruling, "dominant paradigm, which determines the very nature of questions asked and problems posed" (Kuhn, 1970). It was clouded by an a priori belief that the rich World we inhabit is one. And, while ticking off all the boxes that the officially sanctioned research practices demand, in terms of its ultimate relevance and usefulness - it failed.

2.

In 20II, at Keio University, Tokyo, we launched the project Measuring the non-Measurable, one of the most important aims of which was to address precisely that issue. Mn'M included academic and practitioners involved in production of space in ten cities of Asia (Tokyo, Bangkok, Beijing, Hong Kong, Singapore), Australia (Melbourne) and Europe (Barcelona, Belgrade, Copenhagen, Florence). The broad framework was critically informed by Lefebvre's call to address the irreducible oeuvre (1996), while never losing sight of de Certeau's understanding of the city is the most immoderate of human texts (Highmore, 2006). 
As such, the project has explicitly not celebrated efficiency. That made us able to find allies in the depths of thinking such as those of Hélène Cixous, whose ways of reading (which can be translated into the ways of reading that immoderate urban text of ours) deliberately focus "not on a strategically selected detail but on the text in its entirety" (Andermatt Conley, 1992). Such an unorthodox approach to urban research, in which we openly argued for inclusion of the summarily proscribed subjectivity of the researcher, has also found strong support in the latest developments in life sciences. As Sandra Mitchell eloquently explains, in order "to begin to understand many aspects of our complex world ... we need to expand our conceptual frameworks to accommodate contingency, dynamic robustness, and deep uncertainty" (Mitchell, 20I2). Complex realities, "simply", need an intellectual apparatus of matching complexity.

The intention of Mn'M was never to question the importance of quantifiable dimensions of life. One of its critical aims was to argue for an equally respectful treatment of other dimensions of knowing, as neither the quantifiable, not the non-quantifiable alone can fully cover the key dimensions of the synthetic quality which we seek to live. The cities are always in and of a particular place, in and of a particular time. That double contextualisation makes their realities enormously dynamic and complex. The complexity itself and the groundedness in concrete, unique situations are the key aspects of being urban.

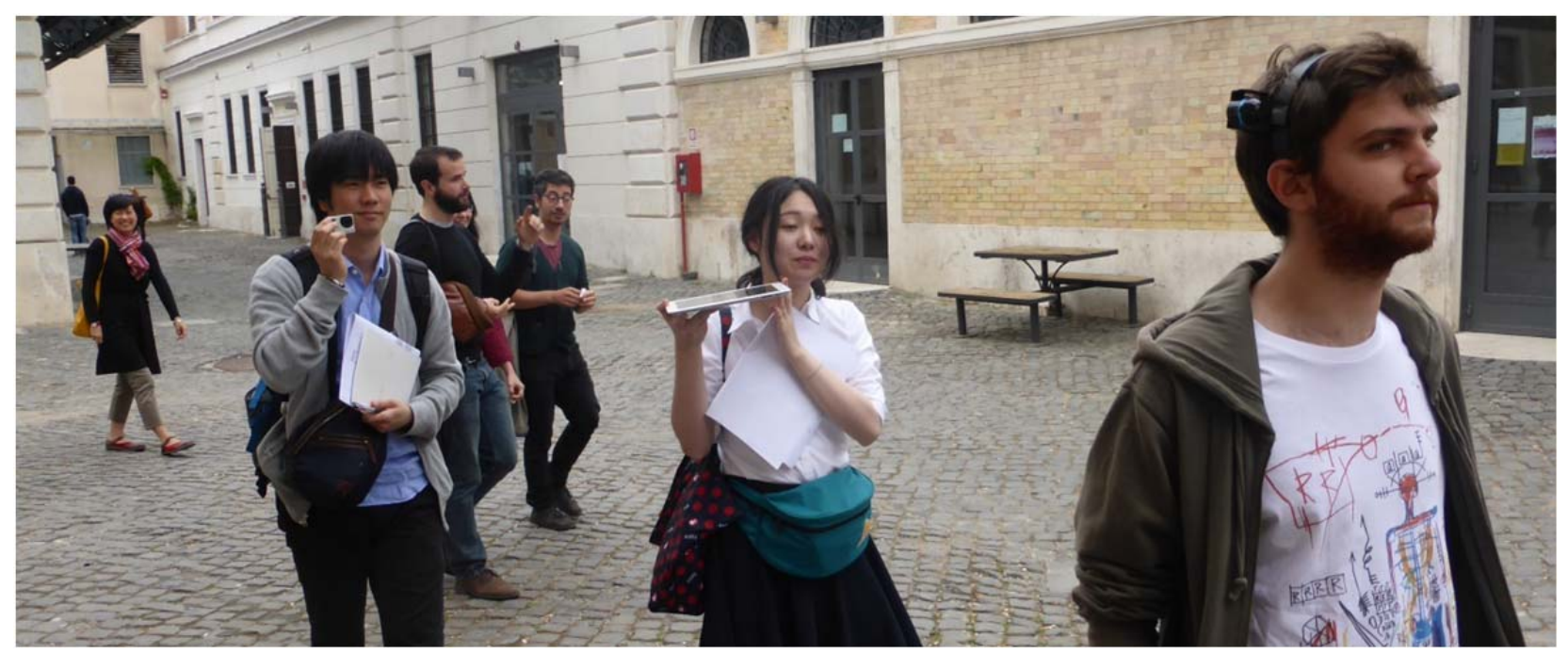

Fig. I co+labo Radović and Mitsukura Laboratory, Keio - urban research fieldwork (Rome, 20I5): confronting recordings of subjective appreciation of urban quality (through interviews, observations, artistic impressions etc.) and the latest in EEG technology

Until recently, much of sciences, "adopted strategies involving reductive explanations designed to simplify the many complexities of nature, in order to understand them" (ibid.). Life sciences have found such limitations too restrictive and unsustainable. The problem is, of course, even more pronounced in the studies of built environments, as they include both the complexities of ecological systems and those of human and social 
Learning, Thinking and Living Tokyo.

Doing urban research in cultures radically different to that of our own

power relations, where precisely the latter produce that crucial quality, the layer that makes human text amazingly immoderate.

If we allow ourselves to lose sight of the untameable complexity of urban phenomena, as well as of the complexity as, in itself, one of the key urban features, if we agree to reduce our understanding of and our interaction with cities, if we narrow them to sets of fragments and fragmentary solutions, we will lose the ability to think, to make, and to live the urban. We will lose urbanity, which cannot be fragmented, and we will, ultimately, lose the human dimension of our habitat.

In that sense, the complexity of the approaches means a better chance to (re)discover fully human ways towards comprehension and, in production of environments, good urbanism, profoundly humane environments.

3.

On the side-lines of Mn'M, we investigated which aspects of urban complexity tend to get excluded from the officially sanctioned practices. Briefly summarised (from Radović, 2014), rigorous application of rigid research frameworks exclude precisely the subtleties which make some of the most fragile, most beautiful and most precious dimensions of the urban. The concepts such as beauty, which are so important, which are part of what makes our species special, came under suspicion. As ultimately subjective, they could not be subjected to pedantic definition and accurate accounting. The same applies to multisensory experiences. The previous knowledges were totally excluded. The singular replaced the plural, in order to enthrone new, pure epistemological framework, an exclusive paradigm of modernity. The emphasis started to move from cumulative and evolutionary, towards futuristic and revolutionary.

In production of space, in urbanism and architecture, the loss of experiential depth (Harvey, 1990), which came from an ever-increasing domination of the modernist urge, remains favoured and generously supported by the power of Spectacle. "The only sense which is fast enough to keep pace with the astounding increase of speed in the technological world is sight" (Pallasmaa, 2005). The Spectacle prefers "the world of the eye", as it is "causing us to live increasingly in a perceptual present, flattened by speed and simultaneity" (ibid.), in which the artificial realities of money and financial power operate best. Domination of the optical introduced a particular kind of "hygiene" which fears complexity. "The contemporary city is increasingly the city of the eye", which has superseded the "haptic city" of the past (ibid.), producing the shopping-centre-like sterilities, which get confused for the new urban(ism). Even the universal and, at the same time, also always culture-and place-specific shadows of Junichiro Tanizaki, Rembrandt or Caravaggio, those of the interiors of the Mediterranean house, vanish to give way and open our realities to pornographic gaze, surveillance, and characterless neon and LED lighting.

Since economy was proclaimed a science, and especially after it became equated with politics, its logic has conquered (much of the) world. Such economy-cum-politics is governed by the Spectacle which seeks power for the few, and (whenever reasonably achievable), panem at circenses, enough food and entertainment to its subjects. That 
power has constructed its own language that, in that historically proven way, rhetorically (re)organized the world in keeping with its (new, always new) views, and set out to convert others to their program. The unconverted ones are - the heretics.

When emphasising how the events and processes 'necessarily exceed our capacity to know them', Law actually stresses the 'beauty of being in the world', the very existence of the unknowable - the search for which, besides cogito, makes us human.

Sentio ergo sum'.

Facing the limits of our ability to rationalise needs courage, the courage of even higher order than what is necessary to unveil the truths (or - the "truths"), scientific - or otherwise.

An ability to appreciate, in parallel, and in addition to (and absolutely not as replacement for) the need to comprehend, is exactly what has been lost by application of exclusive, progressist methods in addressing the aporias of the urban.

4.

That which comes from an overall unease to face situations, cannot be tamed and conquered to fit dominant epistemological frameworks. Despite the rhetoric, the power which fuels current globalisation has difficulties to acknowledge even the existence, let alone the importance of Derridean tout autre, of true and radical difference. That is because such otherness "cannot be made transparent to the understanding and thereby dominated and controlled" (Hillis Miller, 2000). As any heresy, it is subversive and, consequently, highly undesirable. On the other hand, the urban, as an essential theatre of co-presences, is exactly where the very Otherness of the Other plays out one of the most significant roles in creating the magic, irrepressible complexity of cities. It includes some of the most subversive (urban rights) - such as Lefebvrian droit à la ville, the renewed right to the city, le droit a la difference, the right to difference ie. the right to be empowered and to be different, and rights to (each particular) city and to (each particular) urbanity, as fullydeveloped local cultures (Radović, 2008).

Subjectivity and sensuality are political and subversive. As Mack puts it, "the contemporary exclusion of subjectivity amounts to the increasing abrogation of democracy and politics [...] In a society wherein we can appeal to nothing else but the calculating processes of law and economics, individuality as well as diversity lose their political foundations" (Mack, 2014). The Spectacle (Debord, 1994, 1998) thus, banalises and reduces sensuality to sexuality, and sexuality to pornography - in the way it reduces everything to the (monetary) numerical. The opposing project is in search for the complexity lost.

The Spectacle leaves a false impression that "anything goes", while the realities it produces tells exactly the opposite. The power which fuels globalisation of the neo-liberal kind is very efficient in exterminating ideological opposition. The kind of inclusiveness of looking at cities which we advocate here is not an extension of the Post Modern "nonideological", banal pastiche. On the contrary, it has to be based on a strong value system, which is in opposition to the ruling doctrine. This is a value system which rejects its own 
Learning, Thinking and Living Tokyo.

Doing urban research in cultures radically different to that of our own

ossification into a new totalitarian ideology. Getting there, demands a new kind of thinking, and decisive individual responsibility.

The urban is inevitably ideological and political. Ideology and politics of the urbane are those of the common good. Over the last several decades, the urban has been reduced to urbo-economic, in parallel to, and as yet another expression of the reduction of citizens to the consumers.

Therefore, what gets taken out from urban research and action is the fullness of our humanity, and the awareness that, in order to meet our individual and social needs, we seek humane environments which can nourish the best we can all give and live. We will focus on two dimensions of urban research which have been neglected and ostracized, as they cannot fit the insatiable growth machine of the Spectacle - our subjectivities and our sensualities.

5.

Some situations enhance the sense of self and make one extremely aware of own subjectivity, and the inevitability, necessity, and potential of our reliance on deeply personal insights. Such is the condition of extreme cultural foreignness (of the researcher).

For more than two decades now, I have lived in cultures which are profoundly different from that of my own. I do much of my research in the exact places where I live, with focus wide (or narrow) enough to include my own vécu. That makes inroads into objects of my investigation inevitably (self) referential, forming the fields of potential (dis)similarities, causing inspirational (mis)understandings and diverse cross-cultural resonances. Attempts at reconciling my own external and increasingly internalised views opens often conflicting new perspectives, and hints at the various possibilities and degrees of entry. In any case, when exploring the cultures and thought of the Other, "only crossing thresholds and 'entering"' (Jullien, 2015) might be possible.

Research demands definite terms. In cross-cultural research we have to accept an impossibility of having them. Often, there simply is no equivalence, and we need to defy the orthodoxy by specifying contextual definitions.

For instance, to me, initially, the realisation that Japanese language (along many other nonWestern languages, including East and South East Asia) has no words equivalent to the term "public" (Radović, 2010, 20I4) was not easy to comprehend. That absence indicates an absence of, or at least a very unusual situation with, the very concept of public - which is one of the cornerstones of my cultural, professional and academic frameworks. Neither the transcribed paburiku [パブリック], nor the Japanese indigenous kōkyo [公共の] encapsulate the meaning of public. We have to accept that that concept is simply among those "in which other cultures have shown hardly any interest, to the extent that often they do not even have name for it" (Jullien, 20I4). The West has proclaimed its own concept universal, and imposed them on the socio-cultural contexts of the rest. And "we" continue to expect the acceptance; "we" continue to impose them. Similar is the 
situation with a number of other, equally foundational terms and concepts, such as culture, philosophy, aesthetics, logic, rights, or even beauty (Jullien, 20I6).

The terms considered simple and easy, such as piazzas, squares, lanes, or alley are also not easy to translate to many languages. That is because they do not stand for any exact scientific constructs, but for spatial expressions of lived, ephemeral, culturally-specific, social phenomena. There is no universal "alley as such". Urban type which we name "alley" is a product of particular patterns of inhabitation and life. It would be surprising if anything similar, let alone the same, has spontaneously developed in a faraway Japan, or China. We need to ask if connotations of the word alley (can) correspond to those of roji, or sokak, or soi, or calle, or kala, or ... Such questions should not be asked in the name of empty political correctness, but because of the need to recognise the reality of cultural diversity, authenticity, uniqueness, arising from the loci of our projects. The placed identity identifies place.

Living in places of radical cultural difference develops an ability to doubt. The life itself puts to test even "what I can not imagine doubting" (Jullien, 20I5), and one needs to be(come) able to embrace the unease which such doubts cause. Living within the environments of the Other, we first have to "begin to question ourselves" (ibid.), according to local perspective and "according to its implications and expectations" (ibid.).

6.

Ferrarotti's decision "that I prefer not to understand, rather than to colour and imprison the object of analysis with conceptions that are, in the final analysis, preconceptions" (Daley, 1986) is a worthy aim, and a must for the much-needed foreigner-researcher of a new kind (the one who does not seek to educate, but to observe and engage). That is a worthy aim, both hard and rewarding to live.

\section{Note}

(I) Adapted from "Cogito, ergo sum", a philosophical proposition by René Descartes, namely "I think, therefore I am". The author is using the expression "Sentio, ergo sum", namely "I fell, therefore I am" to emphasize the human sensitivity to understand the urban environment.

\section{References}

Andermatt Conley, V. (1992), Hélène Cixous, Toronto: University of Toronto Press. Dale, R. 1986, The Myth of Japanese Uniqueness, Oxford: University of Oxford. de Certeau, M. (1984), The Practice of Everyday Life, Berkeley: University of California Press. Debord, G. (1994), Society of the Spectacle, New York: Zone Books.

Debord, G. (1998), Comments on the Society of the Spectacle, London: Verso.

Harvey, D. (1990), The Condition of Post-Modernity, Molden: Blackwell Publishing.

Hillis-Miller, J. (200I), Others, Princeton and Oxford: Princeton University Press.

Highmore, B. (2006), Michel de Certeau, Analyzing Culture, London, New York: Continuum

Publishing.

Invisible Committee (2009), The Coming Insurrection, Semiotext(e), Intervention series. 
Learning, Thinking and Living Tokyo.

Doing urban research in cultures radically different to that of our own

Jullien, F. (20I4), On the Universal, Cambridge: Polity Press.

Jullien, F. (2015), The Book of Beginnings, New Heaven:Yale University Press.

Jullien, F. (2016), The Strange Idea of the Beautiful, London: Seagull Press.

Kuhn. T. (1970), The Structure of Scientific Revolutions, Chicago: University of Chicago Press.

Lefebvre, H. (1996), Writings on Cities, Cambridge, MA." Blackwell.

Mack, M., (20I4), Philosophy and Literature in Times of Crisis, Challenging our Infatuation with Numbers, New York, London: Bloomsbury Publishing.

Mitchell, S. (2012), Unsimple Truths: Science, Complexity, and Policy, Chicago: University of Chicago Press.

Pallasmaa, Y. (2005), The Eyes of the Skin, Chichester: John Wiley \& Sons Ltd.

Radović, D. (2008), Another Tokyo - places and practices of urban resistance, University of Tokyo, ichii Shobou.

Radović, D., Boontharm, D. (20I4a), In the Search of Urban Quality: 100 maps of Kuhonbutsugawa Street, Tokyo: flick Studio.

Radović, D. (2014b), Subjectivities in Investigations of the Urban: the Scream, the Mirror, the Shadow, Tokyo: flick Studio. 